\title{
Effect of passive smoking on thyroid function in infants
}

\author{
A Gasparoni, M Autelli ${ }^{1}$, M F Ravagni-Probizer ${ }^{4}$, A Bartoli ${ }^{2}$, M Regazzi-Bonora $^{2}$, G Chirico ${ }^{3}$ and G Rondini $^{3}$ \\ Research Laboratories (Pediatric Oncohaematology and Neonatal Immunology), ${ }^{1}$ Biochemical Laboratory, ${ }^{2}$ Department of Pharmacology and \\ ${ }^{3}$ Division of Neonatal Intensive Care, Policlinico San Matteo, IRCCS, Pavia, Italy and ${ }^{4}$ Department of Obstetrics and Gynaecology, University of Pavia, \\ Pavia, Italy
}

(Correspondence should be addressed to A Gasparoni, Divisione di Patologia Neonatale e Terapia Intensiva, Policlinico San Matteo, IRCCS, Piazzale C Golgi, 27100 Pavia, Italy)

\begin{abstract}
Objective: To evaluate the effect of passive smoking on thyroid function in infants. Design and methods: Cord serum tri-iodiothyronine $\left(\mathrm{T}_{3}\right)$, free $\mathrm{T}_{3}\left(\mathrm{fT}_{3}\right)$, thyroxine $\left(\mathrm{T}_{4}\right)$, free $\mathrm{T}_{4}\left(\mathrm{fT}_{4}\right), \mathrm{TSH}$, thyroxine binding globulin (TBG), thyroglobulin (TG) and cord plasma thiocyanate were measured at birth, and serum TG and thiocyanate after 1 year of life, in 18 infants born from parents who did not smoke (group A), in 18 infants with a father who smoked (group B) and in 18 infants with parents both being smokers (group C).

Results: No significant differences were observed in cord serum concentrations of $\mathrm{T}_{3}, \mathrm{fT}_{3}, \mathrm{~T}_{4}, \mathrm{fT}_{4}$, TSH and TBG among the three groups. Median (range) TG concentrations (ng/ml) were 30.2 (5.0-102.0), $56.3(20.5-208.0)$ and $76.0(26.0-199.0)$ at birth $(P=0.009$ for groups A and B compared; $P=0.0002$ for groups $A$ and $C$ compared), and 14.9 (5.4-32.0), 19.5 (10.0-57.5) and $20.0(14.0-40.7)$ at 1 year $(P=0.017$ for groups $A$ and $C$ compared), in the three groups respectively, and thiocyanate concentrations (mmol/l) were $3.3(0.0-51.4), 12.9(0.0-122.2)$ and 27.8 (3.3-184.5) at birth $(P=0.015$ for groups A and $C$ compared), and 3.1 (0.0-32.7), 6.0 $(0.0-47.3)$ and $20.3(0.0-230.8)$ at 1 year $(P=0.01$ for groups $A$ and $C$ compared $)$ in the three groups respectively.

Conclusions: TG and thiocyanate concentrations at birth and at 1 year of age in infants of smoking parents are greater than in infants with non-smoking parents. These results indicate that the change in thyroid function as evaluated by serum TG concentrations observed at birth can persist at least for 1 year if the exposure to passive smoking from both parents is continued. Increased TG concentrations may be due to a direct effect of thiocyanate on the thyroid gland.
\end{abstract}

European Journal of Endocrinology 138 379-382

\section{Introduction}

Several researchers have evaluated the negative effects of exposure to cigarette smoke during pregnancy on the fetus and reported a correlation with low birth weight and increased frequency of respiratory disease and learning or behavioural problems. The causes have not been completely identified and remain the subject of investigation (1-4).

The habit of smoking can affect thyroid function. Thiocyanate, derived from hydrogen cyanide, leads to increased excretion of iodine, seems to inhibit iodine uptake by the thyroid, and can have a goitrogenic effect in the presence of iodine deficiency (5-7).

In view of the significant correlation that has been reported between cord blood concentrations of thiocyanate and thyroglobulin (TG) (5), suggesting a direct effect of thiocyanate on the thyroid gland, our aim was to follow infants to 1 year of age, in order to explore the hypothesis that an altered thyroid function can persist in consequence of protracted exposure to passive smoking.

\section{Subjects and methods}

We investigated three groups of children, born in the Section of Neonatology of our Division of Neonatal Intensive Care during a 4-month period: group A comprised 18 infants with mean ( \pm S.D.) birth weight $3251 \pm 311 \mathrm{~g}$, born to parents who did not smoke and were not exposed to smoke either at home or at work; group $\mathrm{B}$ were 18 infants with mean birth weight $3296 \pm 353 \mathrm{~g}$, with a smoking father and a nonsmoking mother; group $\mathrm{C}$ were 18 infants with mean birth weight $2985 \pm 373 \mathrm{~g}$, whose parents both were smokers. Group B were included to evaluate the risk for the fetus of the exposure of the non-smoking mother to passive smoking. 
All the mothers were healthy and none of them developed postpartum thyroiditis. All the infants were born at term (gestational age 39-41 weeks), after normal pregnancy and delivery, had birth weights appropriate for gestational age and Apgar scores of 9 or 10 at $5 \mathrm{~min}$. Infants with malformations, prematurity or other severe diseases were excluded from the study, as were infants born after complicated pregnancy or delivery, as mode of delivery can influence TG concentrations (8).

Smoking parents consumed at least 10 cigarettes per day (more than 180 packs per year) during gestation and the first year after delivery. No significant factors besides smoking habit, such as socio-economic status, work environment or type of feeding, were noted that could influence exposure to thiocyanate in the parents of the three groups of infants.

After informed consent was obtained from the parents, samples were collected of maternal blood $(2 \mathrm{ml})$ to exclude contamination, cord blood $(2 \mathrm{ml})$ and peripheral blood of the child at 1 year of age $(1 \mathrm{ml})$. Serum tri-iodiothyronine $\left(\mathrm{T}_{3}\right)$, free $\mathrm{T}_{3}\left(\mathrm{fT}_{3}\right)$, thyroxine $\left(\mathrm{T}_{4}\right)$, free $\mathrm{T}_{4}\left(\mathrm{fT}_{4}\right)$, thyroid-stimulating hormone (TSH), thyroxine-binding globulin (TBG) and TG and plasma thiocyanate concentrations were measured in cord and mother's blood; when the children were 1 year of age, because of the limited amount of available samples, only TG and thiocyanate were assessed in 14 children of group A, 16 of group B and 10 of group C.

All the samples were centrifuged; two aliquots of serum and plasma were separated and stored at $-20^{\circ} \mathrm{C}$ until required for determinations.

$\mathrm{T}_{3}, \mathrm{fT}_{3}, \mathrm{~T}_{4}, \mathrm{fT}_{4}, \mathrm{TSH}, \mathrm{TBG}$ and TG were measured with a fluoroimmunological assay (Delfia-Wallac OY, Turku, Finland). Anti-thyroglobulin antibodies were evaluated by RIA (RIA kit Sorin, Saluggia, Italy) in both infants and mothers.

Thiocyanate was assayed with standard colorimetric methods available for the determination of small amounts of thiocyanate in biological fluids, based on the method developed by Aldridge (9) and Epstein (10) and modified by Jimenez et al. (11). The method was based on the chemical reaction of thiocyanate with $\mathrm{Fe}\left(\mathrm{NO}_{3}\right)_{3}$ reagent, producing a coloured complex. The absorbance of the resultant reddish-brown dyestuff was read against a blank reagent at a wavelength of $470 \mathrm{~nm}$. For sample preparation, a $0.5 \mathrm{ml}$ aliquot of plasma with $2 \mathrm{ml}$ water was de-proteinized by the addition of $2.5 \mathrm{ml}$ trichloroacetic acid (10\%). The precipitate was discarded and $2 \mathrm{ml}$ of the supernatant was treated with $2 \mathrm{ml} \mathrm{Fe}\left(\mathrm{NO}_{3}\right)_{3}$ reagent. Samples were read within 15 min against a blank reagent at the wavelength of $470 \mathrm{~nm}$. The blank consisted of $1 \mathrm{ml}$ water, $1 \mathrm{ml}$ trichloroacetic acid and $2 \mathrm{ml}$ ferric reagent $(80 \mathrm{~g}$ $\mathrm{Fe}\left(\mathrm{NO}_{3}\right)_{3} .9 \mathrm{H}_{2} \mathrm{O}, 34.6 \mathrm{ml} \mathrm{HNO}_{3} 65 \%$ and water to a volume of $500 \mathrm{ml}$ ). Plasma standards were prepared daily by adding known amounts of a standard solution of ammonium thiocyanate to human plasma. A standard curve was constructed by performing a linear regression of absorbance versus thiocyanate concentration $(2.5-942.9(\mathrm{~mol} / \mathrm{l})$. The lower limit of sensitivity was $1 \mathrm{~mol} / \mathrm{l}$ (coefficient of variation $12 \%$ ).

The infants were evaluated for clinical history, growth (weight, height and head circumference percentiles calculated following Gairdner's and Pearson's 24 weeks to 2 years growth charts) and development (complete neurological examination) at 1, 6 and 12 months of age.

The study was approved by the Ethics Committee of the Hospital of Pavia.

Non-parametric statistical analysis was performed using Kruskal-Wallis ANOVA, the Mann-Whitney U test and Spearman's rank correlation. $P<0.05$ was considered significant. All computations were performed using a commercial statistical package (STATISTICA for Windows, StatSoft, Inc, Tulsa, OK, USA).

\section{Results}

Assay for anti-thyroglobulin antibodies gave negative results in both infants and mothers. No significant relationships were observed between mothers' and infants' thyroid hormone concentrations.

Birth weight was significantly lower in infants with smoking parents than in controls or infants with only a father who smoked $(P=0.026)$.

Tables 1 and 2 show the results concerning thyroid hormones and thiocyanate concentrations in the infants.

No significant differences were observed in the concentrations of $\mathrm{T}_{3}, \mathrm{~T}_{4}, \mathrm{fT}_{3}, \mathrm{fT}_{4}$, TSH and TBG in the cord blood of the three groups, but the concentrations of TG were significantly lower in group A than in groups B $(P=0.009)$ and $C(P=0.0002)$. Thiocyanate concentrations in cord blood did not differ between groups A and $\mathrm{B}$, whereas group $\mathrm{C}$ had higher concentrations than group A $(P=0.015)$.

At 1 year of age, the differences between serum TG concentrations remained significant only between groups $\mathrm{A}$ and $\mathrm{C}(P=0.017)$. Similarly, thiocyanate concentrations at 1 year of life were significantly different between groups $\mathrm{A}$ and $\mathrm{C}(P=0.01)$, but not between groups $\mathrm{A}$ and $\mathrm{B}$.

No significant differences in growth and development among the three groups were found during follow-up at 1,6 and 12 months of age, and no alterations of the sleep-wake rhythm or irregularity of the alvus were observed, in either breast- or formula-fed infants.

\section{Discussion}

Several authors have reported the presence of metabolites of nicotine in adults and children exposed to passive smoke (12-14). Among the metabolites, the influence of thiocyanate on thyroid function has received 
Table 1 Cord blood serum thyroid hormone and thiocyanate concentrations in the three groups of infants. Values are median and range.

\begin{tabular}{cllllllcc}
\hline & $\begin{array}{c}\mathbf{T}_{\mathbf{3}} \\
(\mathrm{ng} / \mathrm{ml})\end{array}$ & \multicolumn{1}{c}{$\begin{array}{c}\mathbf{T}_{\mathbf{4}} \\
(\mu \mathrm{g} / \mathrm{dl})\end{array}$} & $\begin{array}{c}\mathbf{f T}_{\mathbf{3}} \\
(\mathrm{pg} / \mathrm{ml})\end{array}$ & $\begin{array}{c}\mathbf{f T}_{\mathbf{4}} \\
(\mathrm{pg} / \mathrm{ml})\end{array}$ & $\begin{array}{c}\text { TSH } \\
(\mathrm{U} / \mathrm{ml})\end{array}$ & $\begin{array}{c}\text { TBG } \\
(\mu \mathrm{g} / \mathrm{ml})\end{array}$ & $\begin{array}{c}\text { TG } \\
(\mathrm{ng} / \mathrm{ml})\end{array}$ & $\begin{array}{c}\text { Thiocyanate } \\
(\mu \mathrm{mol} / \mathrm{l})\end{array}$ \\
\hline Group A & 0.5 & 9.3 & 1.5 & 10.0 & 4.5 & 33.7 & $30.2^{*}$ & $3.3^{* *}$ \\
$\quad(n=18)$ & $0.2-1.7$ & $5.7-11.4$ & $1.2-2.5$ & $8.7-11.4$ & $1.7-12$ & $11.3-54.6$ & $5.0-102.0$ & $0.0-51.4$ \\
Group B & 0.6 & 9.5 & 1.4 & 9.2 & 6.7 & 35.5 & 56.3 & 12.9 \\
$\quad(n=18)$ & $0.3-6.1$ & $7.6-15.7$ & $1.1-1.9$ & $8.0-12.2$ & $3.0-47.5$ & $25.5-66.2$ & $20.5-208.0$ & $0.0-122.2$ \\
Group C & 0.5 & 9.7 & 1.5 & 9.6 & 4.9 & 35.5 & 76.0 & 27.8 \\
$(n=18)$ & $0.3-0.7$ & $5.0-12.4$ & $1.1-1.9$ & $8.2-11.7$ & $3.0-13.5$ & $23.9-48.4$ & $26.0-199.0$ & $3.3-184.5$ \\
\hline
\end{tabular}

${ }^{*} P=0.009$ compared with group $B$ and $P=0.0002$ compared with group $C ;{ }^{* *} P=0.015$ compared with group $\mathrm{C}$.

Table 2 Serum thyroglobulin (TG) and thiocyanate concentrations in the three groups of infants at 1 year of age. Values are median and range.

\begin{tabular}{ccc}
\hline & TG $(\mathrm{ng} / \mathrm{ml})$ & Thiocyanate $(\mu \mathrm{mol} / \mathrm{l})$ \\
\hline Group A & $14.9^{*}$ & $3.1^{* *}$ \\
$(n=14)$ & $5.4-32.0$ & $0.0-32.7$ \\
Group B & 19.5 & 6.0 \\
$(n=16)$ & $10.0-57.5$ & $0.0-47.3$ \\
Group C & 20.0 & 20.3 \\
$(n=10)$ & $14.0-40.7$ & $0.0-230.8$ \\
\hline
\end{tabular}

${ }^{*} P=0.017$ compared with group $\mathrm{C} ;{ }^{* \star} P=0.01$ compared with group C.

particular attention $(5,15,16)$, both in vivo and in vitro, with conflicting results. Increased TG levels $(5,16)$, reduced TSH concentrations (17-19), associated unaltered (17) or increased $\mathrm{T}_{4}$ concentrations (18), and reduced (16) or normal (19) $\mathrm{T}_{3}$ concentrations have been reported. Because thiocyanate crosses the placenta, the studies have been extended to both mother and fetus.

Thiocyanate, derived from hydrogen cyanide, has a biological half-life of 1-2 weeks. Therefore, measurements in plasma may be used to detect the degree of exposure to cigarette smoking from days to weeks after the last consumption. The following effects of thiocyanate on thyroid function have been observed in animals: inhibition of iodide transport, increased iodide efflux, inhibition of iodide organification and reduction of the iodination of the molecules that bind to TG (6).

Thyroglobulin is a large glycoprotein that functions as a reservoir for the thyroid hormones and their precursors. Furthermore, it binds several iodized molecules: aminoacids (mono-iodothyronine and diiodothyronine), iodized dipeptides, proteins such as iodoalbumin, and others. It is released in small amounts from the thyroid into the circulation. Low serum concentrations of TG are usually found in infants with thyroid dysgenesis or defects of TG synthesis or secretion; undetectable TG usually indicates thyroid aplasia, whereas a finding of TG in the serum indicates that functional thyroid tissue is present. Increased concentrations have been observed in different thyroid disorders and are considered an excellent marker for recurrence of thyroid tumour in patients taking thyroxine. TG does not cross the placental barrier and the concentrations are greater in cord blood than in maternal blood, although the explanation for this finding remains to be clarified. Our results confirmed the gradual reduction of TG concentrations during the first year of life that has been reported by others (8).

The present study confirmed the increased concentrations of cord TG in the infants of smoking parents as previously reported by Chanoine et al. (5); this increase was accompanied by increased concentrations of thiocyanate in group $\mathrm{C}$ compared with group A. Furthermore, it seems that the exposure of the pregnant woman to passive smoking by her partner resulted in a significant passage of the metabolites of nicotine through the placenta, as group B also demonstrated increased concentrations of TG and thiocyanate in cord blood.

The difference in TG concentrations between groups $A$ and $C$ persisted 1 year after birth, whereas it was no longer evident between groups $\mathrm{A}$ and $\mathrm{B}$. This was in accordance with the changes in thiocyanate concentrations. It seemed that, if the period of exposure to passive smoking was prolonged, the alterations in TG concentrations persisted. Interestingly, the difference was observed only when the exposure to paternal smoking at home was added to that of the mother. Possible explanations of the lack of difference between groups A and B 1 year after birth could be that, if the father was smoking he smoked at a considerable distance from the child, or that only an intense exposure to passive smoking from both parents may produce a significant effect on thyroid function.

These findings could be related either to chronic sympathetic stimulation induced by nicotine, or to a direct effect of thiocyanate on thyroid cellular function (20).

Several studies have reported an increased prevalence of goitre in smokers. This was associated with an increase in serum TG and thiocyanate concentrations (7). The increase in the thyroid volume/birth weight ratio observed in newborns appeared to parallel the increase in cord serum thiocyanate concentrations found in infants of smoking mothers, suggesting that 
smoking during pregnancy may be a relevant cause of thyroid gland enlargement in the newborn (5), probably by reducing iodine availability (7).

As no significant influence of parental smoking on the development and growth of the children was observed, study of the effects of passive smoking on thyroid function should be extended to older children, in order to evaluate whether a relation exists between altered thyroid function and behavioural problems observed in children exposed to passive smoking $(21,22)$. The clinical picture observed in adolescents exposed to passive smoking could be due to direct stimulation of sympathetic nervous activity induced by nicotine, superimposed upon the smoking-induced increase in thyroid hormone secretion (8).

\section{Acknowledgements}

We are grateful to nurses S Martinotti and B Tavazzi for help in blood sampling.

\section{References}

1 Chirico G, Locatelli F, Rondini G, Gasparoni A, Severi F, RavagniProbizer MF \& Danesino V. Effect of active and passive smoking on vascular reactivity in mothers and infants. Lancet 198711095 1096.

2 Kahn A, Groswasser J, Sottiaux M, Kelmanson I, Rebuffat E, Franco P, Dramaix M \& Wayenberg JL. Prenatal exposure to cigarettes in infants with obstructive sleep apneas. Pediatrics 1994 $93778-783$

3 Gidding SS \& Schydlower M. Active and passive tobacco exposure: a serious pediatric health problem. Pediatrics 199494 750-751.

4 Spinillo A, Ometto A, Stronati M, Piazzi G, Iasci A \& Rondini G. Epidemiologic association between maternal smoking during pregnancy and intracranial hemorrhage in preterm infants. Journal of Pediatrics 1995127 472-478.

5 Chanoine JP, Toppet V, Boudoux P, Spehl M \& Delange F. Smoking during pregnancy: a significant cause of neonatal thyroid enlargement. British Journal of Obstetrics and Gynaecology 1991 $9865-68$.

6 Fukayama H, Nasu M, Murakami S \& Sugawara M. Examination of antithyroid effects of smoking products in cultured thyroid follicles: only thiocyanate is a potent antithyroid agent. Act Endocrinologica 1992127 520-525.
7 Bartalena L, Bogazzi F, Tanda ML, Manetti L, Dell'Unto E \& Martino E. Cigarette smoking and the thyroid. European Journal of Endocrinology 1995133 507-512.

8 Ericsson UB, Ivarsson SA \& Persson PH. Thyroglobulin in cord blood. The influence of the mode of delivery and the smoking habits of the mother. European Journal of Pediatrics 1987146 44-47.

9 Aldridge WN. Estimating microquantities of cyanide and thiocyanate. Analyst 194469262.

10 Epstein J. Estimation of microquantities of cyanide. Analytical Chemistry $194719272-274$.

11 Jimenez de la Higuera A, Olea MF, Olea $N$ \& Jimenez F. Determination of serum thiocyanate in patients with thyroid disease using a modification of the Aldridge method. Journal of Analytical Toxicology 199418 58-59 (Letter).

12 Schulte-Hobein B, Schwartz-Bickenbach D, Abt S, Plum C \& Nau H. Cigarette smoke exposure and development of infants throughout the first year of life: influence of passive smoking and nursing on cotinine levels in breast milk and infant's urine. Acta Paediatrica 199281 550-557.

13 Klein J, Chitayat D \& Koren G. Hair analysis as a marker for fetal exposure to maternal smoking. New England Journal of Medicine $199332866-67$.

14 Eskenazi B, Prehn AW \& Christianson RE. Passive and active maternal smoking as measured by serum cotinine: the effect on birthweight. American Journal of Public Health 199585 395-398.

15 Bertelsen JB \& Hegedus L. Cigarette smoking and the thyroid. Thyroid 19944 327-331.

16 Sepkovic DW, Marshall MV, Rogers WR, Cronin PA, Colosimo SG \& Haley NJ. Thyroid hormone levels and cigarette smoking in baboons. Proceedings of the Society for Experimental Biology and Medicine 1988187 223-228.

17 Hegedus L, Karstrup S, Veiergang D, Jacobsen B, Skovsted L \& Feldt-Rasmussen U. High frequency of goitre in cigarette smokers. Clinical Endocrinology 198522 287-292.

18 Meberg A \& Marstein S. Smoking during pregnancy. Effects on the fetal thyroid function. Acta Paediatrica $198675762-766$.

19 Ericsson UB \& Lindgarde F. Effects of cigarette smoking on thyroid function and the prevalence of goitre, thyrotoxicosis and autoimmune thyroiditis. Journal of Internal Medicine 1991229 $67-71$.

20 Utiger RD. Cigarette smoking and the thyroid. New England Journal of Medicine 1995333 1001-1002.

21 Fergusson DM, Horwood J \& Lynskey MT. Maternal smoking before and after pregnancy: effect on behavioral outcomes in middle childhood. Pediatrics 199392 815-822.

22 Weitzman M, Gortmaker S \& Sobol A. Maternal smoking and behavior problems of children. Pediatrics $199290342-349$.

Received 13 June 1997

Accepted 6 November 1997 